\section{Rearing conservation projects to maturity - changing the metaphor for conservation success}

"Has there been an improvement in conservation status this year?" asks one of the questions on the annual report form of a major funding body for threatened species conservation in Australia. In this context a recent attempt to measure the overall economic cost-benefit of threatened species conservation divides the annual increase in status by the cost of the conservation programme (Cullen et al., 2001). Economists and politicians evidently believe that the status of threatened species can be transformed like a business - change the management and there should be a profit, or, given the prevalence of environmental health as a metaphor, administer a dose of medicine and the patient will rapidly recover.

The reality, of course, is very different. For any one year the answer to the question is almost always that there has been no improvement in conservation status. A cost benefit analysis is meaningless because the benefit can rarely be measured in terms of status improvement. Again in Australia, just seven birds out of 236 taxa in a threatened category improved in status as a result of conservation management over 1992-2000, less than one per year on an investment of A \$28 million by government and the community (Garnett \& Crowley, 2000). In Australia that is just three for each term of government - not a lot with which to entice the green voter.

This dissonance between funding bodies and biological reality is not confined to the antipodes. Few funding cycles worldwide are for more than 3 years without needing further justification, and with an expectation that some positive trends will be evident as a result of investment. While it is obvious to conservation biologists that it will usually take decades to reverse declines in environmental condition, money and politics are impatient and, dangerously for conservation, are likely to seek activities that can offer a faster return on investment.

Part of the problem is the language used by conservation to gain support from funding bodies. How many campaigns exhort donors to "Save the ...!". While the condor and kakapo can indeed be saved in the shortterm from highly predictable extinction, in most cases we are asking for help to reverse trends, and extinction is highly unlikely in the immediate future. The trouble with urgent exhortation is the past tense. Once government or business has invested for a few electoral cycles, it expects to have 'saved' something, and be in a position to 'save' something else.

Unfortunately one can never save a species from extinction, only increase the chances of its continued persistence. Similarly one can never restore a community, only bring it back to an earlier state on which natural evolutionary processes can continue to operate. Declaration of a National Park is only the first exciting step in what is a perpetual commitment to conservation management. Human communities can never be made sustainable in perpetuity, and all that one can hope to achieve is minimization of their negative environmental impacts for the period that sympathetic political, economic and social factors persist.

How then can we change perceptions of what is possible, and provide measures of success that satisfy both funding bodies and biological reality? One answer may be to change the analogies we use for describing success. Politicians and funding agencies need to learn that managing the environment is more like rearing children than administering medicine. Like conservation projects, children take decades to reach maturity and independence. They are a responsibility that cannot be taken lightly, and remain as such until they reach independence. Many conservation managers will recognize other similarities. For instance, conservation projects:

- are often a labour of love - few conservation managers do it for the money;

- are usually seen to be wonderful in the eyes of their parents (at least in public) - just read the progress reports to funding agencies;

- can nevertheless be stubborn, wilful and capricious particularly in the teenage years when the community takes control of projects from external professionals and the projects become independent;

- often start with disadvantages - too poor, occur in poorer communities, lack charisma - and some may be so disadvantaged that they can never become independent;

- benefit from a stable home, long-term and consistent care, and good education - projects that stop and start frequently usually have unhappy outcomes, and few projects are without some element of environmental education;

- can even look after their parents in old age by providing global environmental benefits. 
Above all, however, neither children nor conservation projects are responsibilities that end after a few funded years.

The analogy with children can also be extended to measuring success in conservation. With children, we assess the level of support needed not on the basis of success or failure but on how much support they need to sustain themselves without assistance. If parents are unable to provide that support then the responsibility falls back onto society. There are various indicators to gauge the level of support needed: in children, birth weight, early reading ability, stability of parental relationships, or level of drug use are often correlated with the way in which people contribute to society as an adult. For all sorts of reasons some people always rely on support from the rest of society to survive. The majority of children learn to cope on their own only after a long period of dependence.

Threatened species, degraded ecological communities and unsustainable societies need similar nurturing and long-term support if they are to persist into the future. In the short-term it may be possible to determine the level of support needed, using variables such as level of threat, extent of community education and involvement, and a suite of short-term biological measures variables that are all likely to be correlated with the long-term well-being of the various environmental outcomes to which individual conservation projects aspire.

For children, longitudinal studies have enabled definition of threshold levels, after which increased levels of support are needed. For conservation there appear to have been no studies of the correlation between shortterm variables and long-term sustainability, and so no thresholds for action have been identified. This should be an important field of conservation research in coming years as more examples of sustained conservation management become available.

Such studies, however, will have to include the many cases where items of high conservation value have had to be 'saved' again and again, to compare the cost and outcomes of pulsed conservation funding with those of continuous long-term support that reflects the true cost of rearing a project through to self-sustaining maturity. Above all, we need to convince politicians that conservation, like education, health and social services, is a perpetual responsibility of government and that, as with each of those, positive change will often take the lives of many parliaments. Children graduate after nearly two decades of education at home and at school.
Changes in conservation status should only be expected with a similar frequency.

\section{Stephen Garnett}

Conservation Biology Group, Zoology Department

University of Cambridge, Cambridge, UK

$\mathcal{E}$

Queensland Parks and Wildlife Service

P.O.Box 2066, Cairns, Queensland 4870, Australia

E-mail: stephen.garnett@epa.qld.gov.au

\section{References}

Cullen, R., Fairburn, G.A. \& Hughey, K.F.D. (2001) Measuring the productivity of threatened species programs. Ecological Economics, 39, 53-56.

Garnett, S.T. \& Crowley G.M. (2000) Action Plan for Australian Birds 2000. Environment Australia, Canberra, Australia.

\section{Note from the Editor}

2003 is the centenary year for both Oryx and Fauna \& Flora International. Oryx will be marking this occasion with a centenary issue in April, and by the production of a CD-ROM of 100 years of Oryx. This invaluable resource will contain the full text of every issue of Oryx from 1903 to 2002, and will be fully searchable. It will be available mid-year, and there will be a further announcement about this in a later issue.

It is my pleasure to report that Oryx is becoming increasingly popular with authors. In 2001 a total of 87 manuscripts were submitted for peer review, an increase of about $30 \%$ over the previous year. Of these manuscripts 43 have been or will be published shortly and 44 have been rejected. As I write in early November 2002 it is clear that there is a similar increase in submissions in 2002, and there will consequently be an average increase of 16 pages per issue in 2003.

The Impact Factor for Oryx for 2001 was 1.36. Impact Factors, which are one measure of the influence of a journal, measure the frequency with which a journal's articles have been cited. These calculations are published by the Institute for Scientific Information (http://www.isinet.com/isi) in the summer following the year of coverage.

Please note that updated Instructions for Contributors are now available (see the inside of the back cover). Amongst other things the new instructions actively encourage electronic submission of manuscripts, and indicate that papers may now include online-only Appendices. 